\title{
DECREASE IN THE INCIDENCE OF CUCUMBER FUSARIUM WILT IN VARAMIN GREENHOUSES USING TALAROMYCES FLAVUS
}

\section{LALEH NARAGHI, DARIUSH SHAHRIARY, ABOLFAZL SARPELEH ASGHAR HEYDARI \& HOMAYOUN AFSHARI-AZAD}

Iranian Research Institute of Plant Protection, Agricultural Research

Education and Extension Organization (AREEO), Tehran, Iran

\begin{abstract}
Fusarium wilt caused by Fusarium oxysporum $f$. sp. cucumerinum is one of the most important greenhouse cucumber diseases. The chemical methods are not possible easily for controlling this disease, and the most suitable of the control method is introduced as biological control using antagonistic agents. Since, the study of antagonistic mechanisms is an important subject in biological control, therefore in this study for isolating pathogenic and antagonistic agents, plant and soil sampling was carried out in the Varamin infected greenhouses. Then, based on the inhibitory percent of the pathogenic agent growth, caused by the antagonistic mechanisms of the different isolates related to the antagonistic fungi, Talaromyces flavus and Trichoderma harzianum, three effective isolates of each one in terms of the most inhibitory effect were selected and the efficacy of the every isolate in biological control was investigated, using three application method (seed coating, addition to soil, both seed coating and addition to soil). In the next step, based on the results of the greenhouse experiment, the four effective treatments containing T. flavus and T. harzianum isolates, in terms of the efficacy in decreasing cucumber Fusarium wilt disease were evaluated in Varamin cucumber greenhouse, during three consecutive crop years. These treatments included TF-Cu-V-59 as soil treatment, TF-Cu-V-60 as seed treatment, TH-Cu-V-13 as soil treatment and THCu-V-13 as soil and seed treatment. Each experiment was performed with a randomized complete block design (RCBD) in five treatments (each of four above-mentioned treatments and unhealthy control) and four replications. The treatments were evaluated as calculating disease severity percent and total yield. Statistical results in compound analysis form for three consecutive years showed that the interaction effect between treatment and year was significant; as a result, analysis of data was carried out for each year, separately. The results related to first and second years showed that among all treatments, the most effective treatment was TF-Cu-V-59 as soil treatment in terms of efficacy in disease control and increasing yield. However, the results related to third year showed that all treatments containing antagonistic isolates decreased disease severity percent and increased yield significantly, compared to unhealthy control. In spite of a significant difference among antagonistic treatments, in terms of disease severity percent and yield, in first and second years, these treatments were not different significantly in third year. It could be presumed that due to the residues of $T$. flavus bioformulations related to previous years in soil, the population of the above-mentioned antagonistic fungus has been improved using antagonistic treatments containing T. flavus in these treatments; consequently there was no significant difference among these treatments in terms of measured parameters.
\end{abstract}

KEYWORDS: Fusarium Oxysporum, Biological Control \& Antagonistic Fungus

Received: Jun 20, 2017; Accepted: Jul 07, 2017; Published: Jul 10, 2017; Paper Id.: IJASRAUG201719

\section{INTRODUCTION}

The latest statistics obtained from the greenhouse products' area, under cultivation have been related to 2014 that, the area under cultivation of the herbs and mushrooms has been indicated 9600 hectars by the Director General of 
the Bureau of greenhouses, of which, 6345 hectares are the vegetable products (Mohammadi and Omid, 2010). About 92 percent of the country's greenhouses are distributed in 12 provinces and the provinces of Tehran, Isfahan, Yazd and Kerman form 70 percent of the country's greenhouses' levels. Among the country's greenhouses' products, the cucumber (Cucumis sativus L.) has the highest area under cultivation. The maximum greenhouse cucumber is produced in Yazd Province that, 348 thousand and 671 tons of the products is obtained from 1125 hectares. Kerman Province, with the production of 260 thousand tons of the cucumber of 1250 hectares of greenhouses, is in the second rank of the country's greenhouse cucumber production.

The average greenhouse cucumber yield is five times of the farm cultivation. The greenhouse cucumber cultivation, as mechanized in addition to the fivefold increase of the average yield to the farm cultivation, the amount of using the input is reduced. Because the greenhouse environment can be controlled and all needed facilities, such as set the temperature, moisture and light, seeds' optimal consumption and pesticides and fertilizers in the greenhouse are available for the producer, the amount of the greenhouse cucumber production is far greater than the farm. The average mechanized greenhouse cucumber is 180 tons per hectare, while in the farms, 30 to 40 tons cucumber is harvested per hectare (Baniameri and Nasrollahi, 2003).

In Iran, in addition to many report on isolating Fusarium oxysporum f. sp. radicis-cucumerinum D.J. Vakalounak as the pathogen of crown and root Fusariumrot of the greenhouse cucumber (Nosrati et al., 2011; Safari et al., 2012; Najafiniya, 2013), the greenhouse cucumber Fusarium wilt caused by Fusariumoxysporum f. sp. cucumerinum (J.H. Owen) is considered as one of the product's important diseases in the cultivation areas of Varamin, Isfahan, Yazd and Kerman (Payghami and Nishabouri, 1992; Nosrati et al., 2011). At present, the common methods to control the disease in the cucumber greenhouses is observing the alternation, using resistant cultivars and chemical pesticides.

Another method of controlling soilborne pathogens is the use of antagonist microorganisms that the need for continued use of agricultural land on the one hand and prevention of environmental problems resulting from the use of chemical fertilizers and pesticides make the agricultural researchers use these microorganisms take effective steps to improve the quantity and quality of agricultural products. Today, in many industrialized countries, instead of using chemical fertilizers and pesticides, all or a part of the nutrients required by plants are provided by the soil microorganisms to the plants, so that, the production and use of biofertilizers in years recent have been increasingly grown (Huang et al., 2011). To use this method, first, an effective biological agent should be selected to control one or a set of the plant diseases (Nelson et al., 1988).

In Iran, in addition to control Fusarium wilt using the methods of crop improvement (determine the appropriate shrubs' intervals and produce healthy seedlings), disinfection of soil with chemical materials such as methyl bromide and dazomet by temperature has been done. Also, a study has been conducted in the field on the possibility of biological control of the disease using antagonist isolates of Trichoderma harzianum (Payghami and Nishabouri, 1992; Heydari and Pesarakli, 2010; Naraghi et al., 2010a, b and c). So, conducting further research in this field seemed necessary. In the present study, after determining the inhibitory effects of isolates of antagonist fungi of Talaromyces flavus and $T$. harzianum on the pathogenic fungus and comparing them in terms of efficiency in reducing the disease index, the top isolates were selected, and the possibility to control the mentioned disease biologically by them was examined in Varamingreen house, with an area of more than five hundred square meters over three successive crop years. 


\section{MATERIALS AND METHODS}

\section{Prepare the Fungus as the Pathogen of the Cucumber Fusarium Wilt Fusarium Oxysporum f. sp. Cucumerinum}

At this stage, according to the previous research results (Gholi-Nyakan et al., 2014), the isolate Fusariumoxysporum f. sp. cucumerinum obtained from Varamin green house soil, with pathogenesis intensity percentage of $85 \%$.

Select Antagonist Treatments of T. Flavus and T. Harzianum by their Application to Examine Varamin Cucumber Greenhouse

According to the results of previous research (Gholi-Nyakan et al., 2012) finally, the top four treatments including antagonist isolates were introduced with their application for review, during three successive crop years in the Varamin cucumber greenhouse. These treatments mentioning the isolate and application included: 1- TF-Cu-V-59 by increasing the soil, 2- TF-Cu-V-60 by increasing the soil and soaked seed, 3- TH-Cu -V-13 by increasing the soil and 4- TH-Cu-V-13 by increasing the soil and soaked seed. It should be noted that all of $T$. flavus isolates (TF-Cu-V-59 and TF-Cu-V-60) and $T$. harzianum (TH-Cu-V-13) were obtained from the soil of Varamin cucumber greenhouses.

Evaluation of the Antagonist Capability of T. Flavus and T. Harzianum isolates on the Cucumber Fusarium Wilt in Varamin Greenhouse

Studies on Varamin cucumber greenhouse were conducted during three successive crop years of 2013, 2014 and 2015. The experiment was performed in a complete randomized block design with five treatments (four treatments with the highest effect on the disease reduction under the greenhouse conditions in Iranian Research Institute of Plant Protection and the control) and four replications. Regarding seven plants per replication, for a total of four replications per treatment 28 plants were used. In this study,the common cultivar of the area cultivation Sultan was used (Figure 1). This study was conducted in research greenhouse of Varamin Plant Patholgy Research Laboratory. The irrigation syatem was set as the tape with an interval of $5 \mathrm{~cm}$ from the shrub stem, so that, the amount of water consumed at the beginning of the cultivation was $100-150 \mathrm{~mm}^{3}$ and was $750 \mathrm{~mm}^{3}$ with the advancement of growth. To feed the plants at the stage after fowering, once per 4 days the fertilizers of nitrogen-phosphorus-potassium (NPK), calcium and microelements were used according to the consumption instructions.

In order to use the treatment affected by the antagonist isolates, the soil was increased according to the use of $25 \mathrm{~kg}$ of T. flavus bioformulation per ha and CFU $/ \mathrm{g} 10^{9}$ or the colony unit per gram (Ruppel et al., 1983; Van Toor et al., 2002). Thus, after calculating the number of spores of the antagonist isolate per gram the relevant bioformulation by Lam hemacytometer and balancing it to reach the number of $\mathrm{CFU} / \mathrm{g} 10^{9}$ through the re-cultivation of this antagonist isolate on the substrate of the bioformulation (if less than the number mentioned) and/ or add the substrate free of the antagonist isolate to bioformulation (in case of more of the above value), the amount consumed was determined for the area tested. For example, for a treatment with four replicates and an area of 500 square meters, $1.25 \mathrm{~kg}$ of the bioformulation was used. Thus, regarding an approximate weight of one kilogram for the volume of soil in an area of one square meter and a height of one centimeter, according to the use of $1.25 \mathrm{~kg}$ of the antagonist bioformulations for 500 square meters, about $1.25 \mathrm{~kg}$ of the $T$. flavus bioformulation equivalent to $1.25 \times 1000 \times 10^{9}$ spores was used for $500 \mathrm{~kg}$ of soil, in other words, per gram of soil, about $2.5 \times 10^{6}$ antagonist fungal spores have been received.

For the treatments, in which, the antagonist isolate was used as soaked seeds, like the application of such 
treatments in the country's Plant Research Institute greenhouse using the bioformulation was, to the extent that, all seed levels weresoaked (Naraghi et al., 2010c). By increasing the bioformulation in the soil, applying such treatments was at the time of transplanting from the planting tray in the greenhouse soil (Figure 2), while in seed treatments, treated seeds were planted in the seedling tray, and then seedlings were transferred to soil.

To ensure needed infection of the greenhouse i.e. at least in the range of $.9 \times 10^{3}$ to $1.345 \times 10^{3} \mathrm{CFU} / \mathrm{g}$, or the colony unit per gram of soil (Anjaiah et al., 2003), the experiment was performed to determine the pathogenic fungus population through soil cultivation on a specific medium (Komada's medium), according to the method Komada (1975). In the lower number of the pathogenic fungus colony unit per gram of the greenhouse soil than the above, before performing the experiment, the artificial bioformulation was prepared on sand and corn substrate with the ratio of 20: 1, according to the method and amount of the bioformulation necessary, with a concentration of CFU / g 1033 (Leeman et al., 1996), and on the basis of $33 \mathrm{~kg}$ per hectare (Elmer, 2002) was distributed throughout the greenhouse soil and mixed with it to a depth of $15 \mathrm{~cm}$ (Hashimoto et al., 2008).

Fusarium wilt disease assessment to determine the percentage of the disease intensity, according to Hao et al. (2005) method began a month after planting and continued for four months (Wokoma et al., 2008). Finally, the treatments were compared through analyzing data by Duncan's Multiple Range Test and using a software program MS TAT C.

To determine the percentage of the intensity of the disease, first the incidence of the disease was specified through observing the symptoms (Figure 3), using a scale of six degrees (Liu et al., 1995) as follows:

Zero $=$ no symptoms

$1=$ The leaf chlorosis and plant wilt less than $25 \%$

$2=$ The leaf chlorosis and plant wilt from 25 to $50 \%$

$3=$ The leaf chlorosis and plant wilt from 51 to $75 \%$

$4=$ The leaf chlorosis and plant wilt from 76 to $100 \%$

$5=$ The dead or completely destroyedplant

Then, the percentage of the disease intensity for each treatment, according to the formula listed for the proof test was calculated as follows:

$\begin{array}{cc}\text { infection severity } & =\underset{\text { percentage }}{\sum\left(\mathrm{n}_{\mathrm{i}} \times \mathrm{v}_{\mathrm{i}}\right)} \\ \mathbf{\mathrm { N }} \times \mathrm{V} & 100\end{array}$




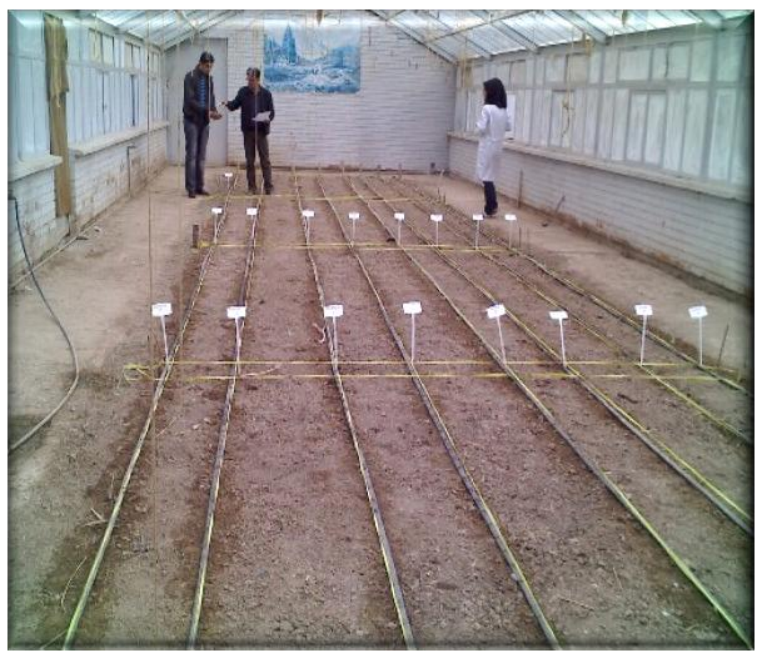

Figure 1: A view of a Greenhouse Plan in a Randomized Complete Block Design
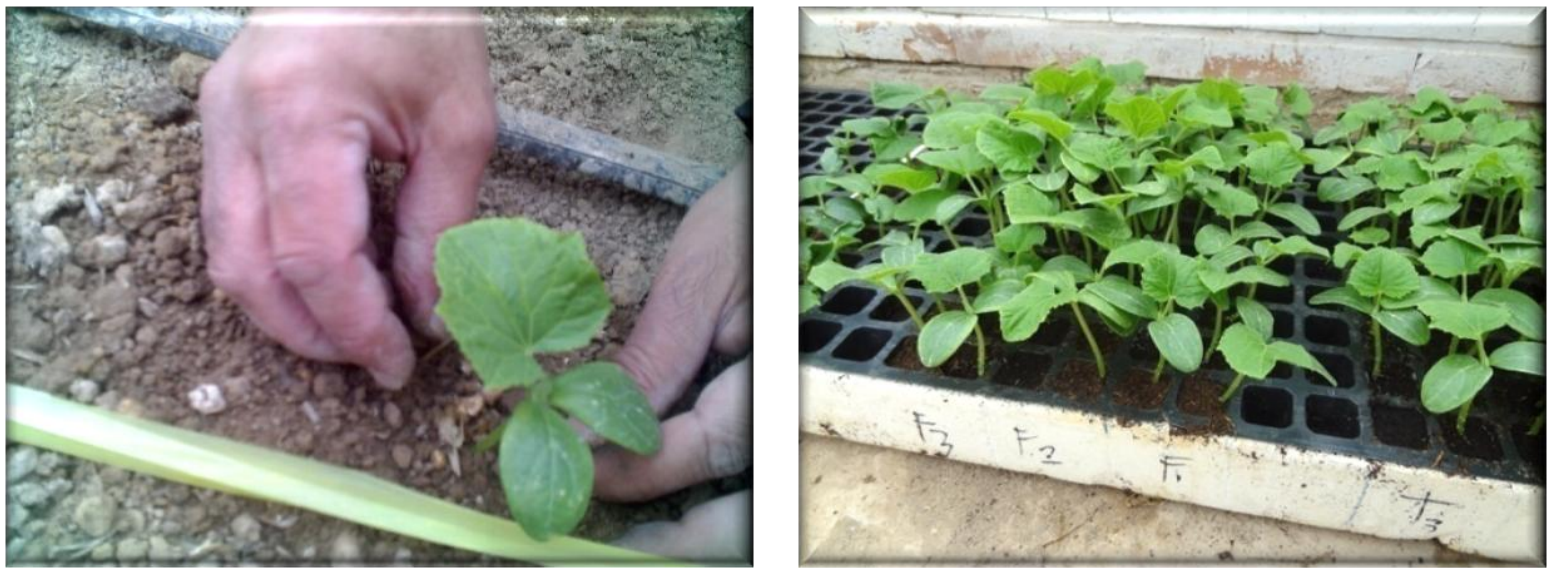

Figure 2: Transplanting from the Planting Tray into the Soil in the Greenhouse

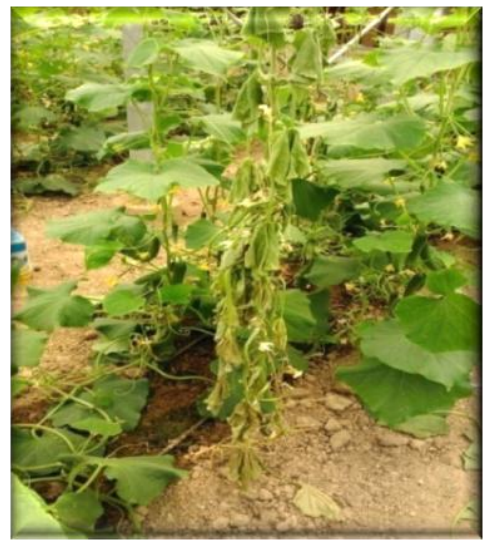

Figure 3: Observe the Symptoms of Fusarium Wilt Disease for Determining its Incidence in Varamin Greenhouse

\section{RESULTS}

Evaluation of the Efficiency of the Treatments of T. Harzianum and T. Flavus in Reducing the Disease Severity Percent and Increasing the Yield

The combined analysis of data related to the disease intensity percentage during three crop years showed that the 
interaction between the year and treatment was significant at the possibility level of $1 \%$, so statistical data analysis related to the disease intensity percentage for each of the 3 years was carried out individually, as follows:

Evaluation of the Disease Severity Percent in the Crop Year 2013

The experiment of the effect of the treatments affected by the antagonistic isolates on the disease severity percent of greenhouse cucumber Fusarium wilt was significant at $1 \%$ probability level. In the mean statistical grouping of the disease intensity percentage, the experiment treatments were in three statistical groups. The results of this classification showed that all treatments compared to the control had a significant reduction in the disease intensity percentage. Among the treatments, the highest disease intensity percentage was related to the treatment of $\mathrm{TH}-\mathrm{Cu}-\mathrm{V}-13$ isolate by increasing the soil and no statistically significant difference was observed among other treatments (Table 1).

Table 1: Comparison of the Disease Severity Percent of Fusarium Wilt in the Treatments of Talaromyces Flavus and T. Harzianum Antagonistic Isolates in Varamin Cucumber Greenhouse in the Crop Year 2013

\begin{tabular}{|l|c|}
\hline \multicolumn{1}{|c|}{ Treatment } & Disease Severity Percent (\%) \\
\hline TF-Cu-V-59 (Soil treatment) & $47.00 \mathrm{c}^{*}$ \\
\hline TF-Cu-V-60 (Soil and seed treatment) & $51.00 \mathrm{c}$ \\
\hline TH-Cu-V-13 (Soil treatment) & $60.00 \mathrm{~b}$ \\
\hline TH-Cu-V-13 (Soil and seed treatment) & $47.00 \mathrm{c}$ \\
\hline Unhealthy Control & $74.00 \mathrm{a}$ \\
\hline
\end{tabular}

$*$ :Among statistically similar letters, there is no significant difference at the level of $1 \%$.

\section{Evaluation of the Disease Severity Percent in the Crop Year 2014}

The experiment of the effect of the treatments affected by the antagonist isolates on the disease intensity percentage of Fusarium wilt of the greenhouse cucumber was significant at $1 \%$ probability level. In the mean statistical grouping of the disease intensity percentage, the experiment treatments were in three statistical groups. The results of this classification showed that all treatments compared to the control had a significant reduction in the disease intensity percentage. Among the treatments, the highest disease intensity percentage was related to the treatment of $\mathrm{TH}-\mathrm{Cu}-\mathrm{V}-13$ isolate by increasing the soil and soaked seeds and no statistically significant difference was observed among other treatments (Table 2).

Table 2: Comparison of the Disease Severity Percent of Fusarium Wilt in the Treatments of Talaromyces Flavus and T. Harzianum Antagonistic Isolates in Varamin Cucumber Greenhouse in the Crop Year 2014

\begin{tabular}{|l|c|}
\hline \multicolumn{1}{|c|}{ Treatment } & Disease Severity Percent (\%) \\
\hline TF-Cu-V-59 (Soil treatment) & $02.00 \mathrm{~b}^{*}$ \\
\hline TF-Cu-V-60 (Soil and seed treatment) & $21.25 \mathrm{~b}$ \\
\hline TH-Cu-V-13 (Soil treatment) & $21.50 \mathrm{~b}$ \\
\hline TH-Cu-V-13 (Soil and seed treatment) & $29.75 \mathrm{ab}$ \\
\hline Unhealthy Control & $43.00 \mathrm{a}$ \\
\hline
\end{tabular}

*: Among statistically similar letters, there is no significant difference at the level of $1 \%$.

\section{Evaluation of the Disease Severity Percent in the Crop Year 2015}

The experiment of the effect of the treatments affected by the antagonist isolates on the disease intensity percentage of Fusarium wilt of the greenhouse cucumber was significant at $1 \%$ probability level. In the mean statistical 
grouping of the disease intensity percentage, the experiment treatments were in three statistical groups. The results of this classification showed that all antagonist treatments compared to the control had a significant reduction in the disease intensity percentage. While among such treatments, no statistically significant difference was observed among other treatments (Table 3).

Table 3: Comparison of the Disease Severity Percent of Fusarium Wilt in the Treatments of Talaromyces Flavus and T. Harzianum Antagonistic Isolates in Varamin Cucumber Greenhouse in the Crop Year 2015

\begin{tabular}{|l|c|}
\hline \multicolumn{1}{|c|}{ Treatment } & Disease Severity Percent (\%) \\
\hline TF-Cu-V-59 (Soil treatment) & $81.78 \mathrm{~b}^{*}$ \\
\hline TF-Cu-V-60 (Soil and seed treatment) & $14.37 \mathrm{~b}$ \\
\hline TH-Cu-V-13 (Soil treatment) & $19.37 \mathrm{~b}$ \\
\hline TH-Cu-V-13 (Soil and seed treatment) & $18.64 \mathrm{~b}$ \\
\hline Unhealthy Control & $30.00 \mathrm{a}$ \\
\hline
\end{tabular}

*: Among statistically similar letters, there is no significant difference at the level of $1 \%$.

\section{Evaluation of the Total Yield}

The combined analysis of data related to the disease intensity percentage during three crop years showed that the interaction between the year and treatment was significant at the possibility level of $1 \%$ (Table 10), so statistic data analysis related to the total yieldfor each of the 3 years was carried out individually as follows:

\section{Evaluation of the Total Yield in the Crop Year 2013}

The experiment of the effect ofthe treatments affected by the antagonistisolatesonthe total yield was significant at $1 \%$ probability level (Table 11). In the mean statistical classification of the total yield, the experiment treatments were in three statistical groups. The results of this classification showed that among the treatments affected by the antagonistisolate the highest average total yieldwas related to the two treatmentsaffected byTH-Cu-V-13 isolate by addition to the soil and seed coating and TF-Cu-V-59 isolate as soil treatment (Table 4).

Table 4: Comparison of the Total Yield in the Treatments of Talaromyces Flavus and T. Harzianum Antagonistic Isolates in Varamin Cucumber Greenhouse in the crop year 2013

\begin{tabular}{|l|c|}
\hline \multicolumn{1}{|c|}{ Treatment } & Total yield $\left(\mathbf{k g}\right.$ per $\left.\mathbf{2} \mathbf{~ m}^{\mathbf{2}}\right)$ \\
\hline TF-Cu-V-59 (Soil treatment) & $33.81 \mathrm{ab}$ \\
\hline TF-Cu-V-60 (Soil and seed treatment) & $23.66 \mathrm{c}$ \\
\hline TH-Cu-V-13 (Soil treatment) & $28.54 \mathrm{bc}$ \\
\hline TH-Cu-V-13 (Soil and seed treatment) & $38.10 \mathrm{a}$ \\
\hline Unhealthy Control & $22.12 \mathrm{c}$ \\
\hline
\end{tabular}

*: Each plot has an area of two square meters.

**: Among the treatments with similar letters, there is no significant difference at the level of $1 \%$.

\section{Evaluation of the Total Yield in the Crop Year 2014}

The experiment of the effect ofthe treatments affected by the antagonistisolatesonthe total yield was significant at $1 \%$ probability level. In the mean statistical classification of the total yield, the experiment treatments were in three statistical groups. The results showed that all treatments containing the antagonistisolate compared to the control had a significant increase in the total yield. Among the treatments, the highest average yield was related to the treatment of TH$\mathrm{Cu}-\mathrm{V}-13$ isolate by increasing the soil. While among other antagonist treatments, no statistically significant difference was 
found in terms of the total yield (Table 5).

Table 5: Comparison of the Total Yield in the Treatments of Talaromyces Flavus and T. Harzianum Antagonistic Isolates in Varamin Cucumber Greenhouse in the Crop year 2014

\begin{tabular}{|l|c|}
\hline \multicolumn{1}{|c|}{ Treatment } & Total yield $\left(\mathbf{k g}\right.$ per $\left.\mathbf{2} \mathbf{~ m}^{\mathbf{2}}\right)$ \\
\hline TF-Cu-V-59 (Soil treatment) & $48.70 \mathrm{a}^{* *}$ \\
\hline TF-Cu-V-60 (Soil and seed treatment) & $29.70 \mathrm{~b}$ \\
\hline TH-Cu-V-13 (Soil treatment) & $34.65 \mathrm{~b}$ \\
\hline TH-Cu-V-13 (Soil and seed treatment) & $29.95 \mathrm{~b}$ \\
\hline Unhealthy Control & $20.80 \mathrm{c}$ \\
\hline
\end{tabular}

*: Each plot has an area of two square meters.

**: Among the treatments with similar letters, there is no significant difference at the level of $1 \%$.

\section{Evaluation of the Total Yield in the Crop Year 2015}

The experiment of the effect of the treatments affected by the antagonist isolates on the total yield was significant at $1 \%$ probability level. In the mean statistical classification of the total yield, the experiment treatments were in three statistical groups. The results showed that all treatments containing the antagonist isolate compared to the control had a significant increase in the total yield. Among such treatments except for the treatment of $\mathrm{TH}-\mathrm{Cu}-\mathrm{V}-13$ isolateby increasing the soil and soaked seeds, no statistically significant difference was found in terms of the total yield (Table 6).

Table 6. Comparison of the Total Yield in the Treatments of Talaromyces Flavus and T. Harzianum Antagonistic Isolates in Varamin Cucumber Greenhouse in the Crop Year 2015

\begin{tabular}{|l|c|}
\hline \multicolumn{1}{|c|}{ Treatment } & Total yield $\left(\mathbf{k g}\right.$ per $\left.\mathbf{2} \mathbf{~ m}^{\mathbf{2}}\right)$ \\
\hline TF-Cu-V-59 (Soil treatment) & $45.60 \mathrm{a}^{* *}$ \\
\hline TF-Cu-V-60 (Soil and seed treatment) & $49.35 \mathrm{a}$ \\
\hline TH-Cu-V-13 (Soil treatment) & $48.50 \mathrm{a}$ \\
\hline TH-Cu-V-13 (Soil and seed treatment) & $43.40 \mathrm{ab}$ \\
\hline Unhealthy Control & $36.40 \mathrm{~b}$ \\
\hline
\end{tabular}

*: Each plot has an area of two square meters.

**: Among the treatments with similar letters, there is no significant difference at the level of $1 \%$.

\section{DISCUSSION AND CONCLUSION}

The study results showed that there is apossibility of the biological control of Fusarium wilt of the cucumber caused by F. oxysporum f. sp. cucumerinum by different isolates of T. harzianum and T. flavus.

This research was done in Varamin cucumber greenhouse, during three successive crop years. The results of the $2^{\text {nd }}$ year of this research in the greenhouses of Varamin also like the first year showed that, there was a possibility of the biological control of Fusarium wilt caused by $F$. oxysporum in the greenhouse cucumber crops by some of the isolates of $T$. flavus and T. harzianum. In the present study, all the treatment affected by isolates of T. flavus (TF-Cu-V-59) by addition to the soil and TF-Cu-V-60 with seed coating and addition to the soil) and T. harzianum (TH-Cu-V-13 by addition to the soil and $\mathrm{TH}-\mathrm{Cu}-\mathrm{V}-13$ with seed coating and addition to the soil), compared with the control had a significant reduction in the disease severity percent, the result was not unexpected according to the results of the research laboratory part, on reducing the growth of the pathogenic colony by the mentioned isolates (Gholi-Nyakan et al., 2014). 
Of course, among the above treatments, despite the first year that the treatment of $\mathrm{TH}-\mathrm{Cu}-\mathrm{V}-13$ by addition to the soil showed lower efficiency in terms of the disease control, compared to other treatments, the lowest efficiency was observed in controlling the disease in the treatment of $\mathrm{TH}-\mathrm{Cu}-\mathrm{V}-13$, by addition to the soil along with seed coating. According to the research on the need for population threshold for the biological agent activity (Lo et al., 1997; Wang, 2012; Mishra et al., 2013), it was likely that in the first year, the needed population of the colony units was not provided for the isolate TH- $\mathrm{Cu}-\mathrm{V}-13$ by only addition to the soil, and in the second year, because of the residual of the bioformulation related to the isolate of the first year, the population of the isolate has reached the desired threshold. Uddin et al. (2011) showed that the occurrence of the population threshold has been possible for some of T. harzianum isolates to control potato seedling death, using seed and soil treatments.

In the first crop year (2013), increase yield up to $33 \%$ in the Trichoderma treatment occurred by addition to the soil and seed coating compared to only addition to the soil, while the disease severity disease in the mentioned treatment by the method of increasing the soil and seed coating also showed a $20 \%$ reduction compared to the increasing the soil. Previous studies in the field ofexamining the effect of different concentrations of various antagonist microorganisms such as T. harzianum and Verticillium lecani $\left(10^{3}, 10^{4}\right.$, and $10^{6}$ the colony unit per $\mathrm{ml}$ of suspension used to provide the seed treatments) on soil borne fungal diseases' control in products, such as tomato, beans and radishes showed that the difference in the colony unit even 1,000 spores in the seed treatment could cause a significant difference in the incidence of Fusarium wilt disease (Leeman et al ., 1996; EliRafai et al., 2003; and Carvalho et al., 2014). Thus, the inference is made that the seed treatment has been significantly important to control vascular diseases such as Fusarium wilt compared to non-vascular diseases.

In the second year, the yield of the isolate $\mathrm{TH}-\mathrm{Cu}-\mathrm{V}-13$ by increasing the soil and seed coating was lower than the first year in terms of reducing the disease severity. Also, for the isolate due to the presence of the bioformulation residual related to the last year, the population of the colony units of the isolate exceeded the threshold and according to the previous studies (Chitarra, 2003) the phenomenon of removing fungalcolony units occurred by the fungus and consequently its antagonist activity has been reduced.

On the other hand, the results of the present study showed that the capability of different antagonistic fungal species (T.flavus and T. harzianum) and even the isolates related to a species (TF-Cu-V-59 and TF-Cu-V- 60) were different in terms of the yield increase. In this field, different efficiency of endophytic fungus isolates Gibberella fujikuroi has been showing on strengthening vegetative traits such as the stem length in some ofdicotyledonous plants including Vitex rotundifolia, soldanella calystegia and Polygonum convolvulus (Khan et al., 2012). In another study, also ContrerasCornejo et al. (2009) showed that the species Trichodermaatroviride and Trichodermavirens due to the difference in the amount and activity of root growth stimulating hormones (auxin and its derivatives), had different strengthening properties for the plant growth.

Also, the results of the $2^{\text {nd }}$ study in Varamin greenhouse showed that for both antagonistic fungi $T$. flavus and T. harzianum, only adding to the soil has been more effective on increasing the yield, in terms of efficiency compared to addition to the soil and seed coating. According to the results of Chitarra (2003) study, reducing the efficiency of some antagonist isolates in the biological control, and thus, reduce the plant yield can be attributed to the reduced population. Thus, the use of high concentrations of spores of antagonistfungi such as Aspergillus and Penicilliumgenus cause a phenomenon known as "Crowding effect". In this phenomenon, the high population of the fungus spores causes producing 
the spore growth inhibitors. For example, the high population of spores of the fungus Penicillium paneum by producing 1octen-3-OL (a combination of oxidative linoleic acid) with a concentration of $4 \mathrm{mM}$ prevents the growth of the spores, thus the fungus antagonist activity is also reduced. On the other hand, the results of the first study in Varamin greenhouse have shown that the method of the soil addition with seed coating compared to only adding to the soil for the isolate TH-Cu-V13 was more effective in terms of efficiency in increasing the yield.Thus, reducing this treatment efficiency in the second year can be attributed to an increase in the population of the colony units of the isolate, because of the presence of the relevant bioformulation of the last year.

Also, the results of the third study in Varamin greenhouse showed that all the treatments containing the antagonist isolate compared to the control had a significant reduction in the disease severity and a significant increase in the yield. And, despite observing a statistically significant difference among antagonistic treatments in terms of the disease severity and yield in the first and second years' studies, no statistically significant difference was found between the treatments. According to the results of anotherstudyin the field of examining the biological control of potato disease Verticillium wilt during two successive crop years (Naraghi et al., 2014a), the inference is made that due to the presence of the residual of $T$. flavus in the soil of the previous years, the use of antagonist treatmentsT. flavus improves the mentioned fungus population in such treatments and lack of a significant difference between them in terms of the traits measured.

The results of the $1^{\text {st }}$ and $2^{\text {nd }}$ years showed that among the treatments, totally the treatment of TF-Cu-V-59 by addition to the soil has been a priority in terms of efficiency, for the disease control and yield increase. While, the results of $3^{\text {rd }}$ year showed that all the treatments containing the antagonistic isolate compared to the control had a significant reduction in the disease severity percent and a significant increase in the yield, and despite observing a statistically significant difference between the antagonistic treatments in terms of the disease severity and yield in the first and second years, no statistically significant difference was found between the treatments in the third year of study. Therefore, it can be stated that due to $T$. flavus residues in the soil from the years before, using $T$. flavus antagonist treatments improves the mentioned fungus population in such treatments, and non-statistically significant difference between them in terms of the traits measured.

\section{REFERENCES}

1. Anjaiah, V., Cornelis, P., and Koedam, N. 2003. Effect of genotype and root colonization in biological control of Fusarium wilts in pigeonpea and chickpea by Pseudomonas aeroginosa PNA1. Canadian Journal of Microbiology, 49 (2): 85-91.

2. Baniameri, V., and Nasrollahi, A. A. 2003. Status of IPM program in greenhouse vegetables in Iran. IOBC/WPRS Bulletin, Additional Abstracts/Papers 26 (10): 1-3.

3. Carvalho, D. D., Junior, M. L., Martins, I., Inglis, P. W., and Mello, S. C. 2014. Biological control of Fusarium oxysporum f. sp. phaseoli by Trichoderma harzianum and its use for common bean seed treatment. Tropical Plant Pathology, 39 (5): 384391.

4. Chitarra, G. S. 2003. Germination inhibitors of fungal spores: Identification and mode of action. Ph.D. thesis Wageningen University, Wageningen, The Netherlands. (with summaries in English and Dutch), 120 .

5. Contreras-Cornejo, H. A., Macías-Rodríguez, L., Cortés-Penagos, C., and López-Bucio, J. Trichoderma virens, a plant beneficial fungus, enhances biomass production and promotes lateral root growth through an auxin-dependent mechanism in Arabidopsis. Plant Physiology, 149 (3): 1579-1592. 
6. EliRafai, I. M., Asswah, S. M., and Awdalla, O. A. 2003. Biocontrol of some tomato disease using some antagonistic microorganisms. Pakistan Journal of Biological Science, 6 (4): 399-406.

7. Elmer, W. H. 2002. Influence of formononetin and NaCl on mycorrhizal colonization and Fusarium crown and root rot of Asparagus. Plant Disease, 86 (12):1318-1324.

8. Gholi Niakan, M., Roustaee, A., Naraghi, L. and Heydari, A. 2012. A comparative study on different antagonistic mechanisms of Talaromyces flavus and Trichoderma harzianum in terms of growth inhibition on Fusarium oxysporum f. sp. cucumerinum, causal agent of greenhouse cucumber wilt disease. Proceedings of $20^{\text {th }}$ Iranian Plant protection Congress, $284 p$.

9. Hashimoto, Y., Nakamura, H., Asaga, K., and Karube, I. 2008. A new diagnostic method for soil- borne diseases using a microbial biosensor. Microbes and Environments, 23 (1): 35-39.

10. Heydari, A., and Pesarakli, M. 2010. A review biological control of fungal plant pathogens using microbial antagonists 10 (4): 273-290.

11. Huang, X., Chen, L., Ran, W., Shen, Q., and Yang, X. 2011. Trichoderma harzianum strain SQR-T37 and its bio-organic fertilizer could control Rhizoctonia solani damping-off disease in cucumber seedling mainly by the mycoparasitism. Applied Microbiology and Biotechnology, 91 (3): 741-755.

12. Khan, S. A., Hamayun, M., Khan, A. L., Lee, I. J., Shinwari, Z. K., and Gukkin, J. 2012. Isolation of plant growth promoting endophytic fungi from dicots inhabiting coastal sand Dunes of Korea. Pakistan Journal of Botany 44 (4): 1453-1460.

13. Komada, H. 1975. Development of a selective medium for quantitative isolation of Fusarium oxysporum from natural soil. Review of Plant Protection Research, 8 (1): 114-125.

14. Leeman, M., Denouden, F. M., Vanpelt, J. A., Cornelissen, C., Matamala-Garros, A., Bakker, P. A. H. M., and Schippers, B. 1996. Suppression of Fusarium wilt of radish by co-inoculation of fluorescent Pseudomonas spp. and root colonizing fungi. European Journal of Plant Pathology, 102 (1): 21-31.

15. Liu, L., Kloepper, J. W., and Tuzun, S. 1995. Induction of systemic resistance in cucumber against Fusarium wilt by plant growth promoting rhizobacteria. Phytopathology, 85 (1): 695- 698.

16. Lo, C. T., Nelson, E. B., and Harman, G. E. 1997. Improved biocontrol efficacy of Trichoderma harzianum 1295-22 for foliar phases of turf diseases by use of spray applications. Plant Disease, 81(10): 1132-1138.

17. Mishra, D. S., Kumar, A., Prajapati, C. R., Singh, A. K., and Sharma, S. D. 2013. Identification of compatible bacterial and fungal isolates and their effectiveness against plant disease. Journal of Environmental Biology, 34 (1): 183-189.

18. Najafiniya, M. 2013. Genetic diversity among Iranian isolates of Fusarium oxysporum $f$. sp. radicis- cucumerinum using vegetative compatibility groups and Rapd molecular maker. Asian Mycological Congress 2013 \& the 13 Internation Marine and Freshwater Mycology Symposium. August 19-23 2013. China National Convention Center (CNCC), Beijing, China.

19. Naraghi, L., Arjmandian, A., Heydari, A., Sharifi, K., and Afshari Azad H. 2014a. A comparison between carbendazim fungicide and Talaromyces flavus in controlling Verticillium wilt of potato under field conditions. International Journal of Agricultural Science and Research, 4: (1): 89-100.

20. Naraghi, L., Heydari, A., Rezaee, S., Razavi, M., and Afshari-Azad, H. 2010a. Biological control of greenhouse cucumber Verticillium wilt disease by Talaromyces flavus. Phytopathologia Mediterranea, 49 (3): 321-329.

21. Naraghi, L., Heydari, A., Rezaee, S., Razavi, M., and Jahanifar, H. 2010b. Study on antagonistic effects of Talaromyces flavus on Verticillium albo-atrum, the causal agent of potato wilt disease. Crop Protection, 29 (7): 658-662.

22. Naraghi, L., Heydari, A., Rezaee, S., Razavi, M., Jahanifar, H., and Mahmoodi Khaledi, E. 2010c. Biological control of tomato 
Verticillium wilt disease by Talaromyces flavus. Journal of Plant Protection Research, 50 (3): 360-365.

23. Nelson, E.B., Harman, G.E., and Nash, G.T. 1988. Enhancement of Trichoderma induced biological control of Pythium seed rot and pre-emergence damping-off of peas. Soil Biology and Biochemistry, 20 (1): 145-150.

24. Nosrati, S., Esmaeilzadeh Hosseini, S. A., Sarpeleh, A., Soflaei Shahrbabak, M., and Soflaei Shahrbabak, Y. 2011. Antifungal activity of spearmint (Mentha spicuta L.) essential oil on Fusarium oxysporumf. sp. radicis- cucumerinum the causal agent of stem and crown rot of greenhouse cucumber in Yazd, Iran. International Conference on Environmental and Agriculture Engineering, Vol.15, IACSIT Press, Singapore, 52-56.

25. Payghami, E., and Nishabouri, M. R. 1992. Studying of biological control of cucumber Fusarium wilt by Trichoderma harzianum Rifai. Plant Disease, 2 (3,4): 102-133.

26. Ruppel, E. G., Baker, R., Harman, G. E., Hobbard, J. P., Hecker, R. J., and Chet, I. 1983. Field test of Trichoderma harzianum Rifai Aggr. As a biocontrol agent of seedling disease in several crops and Rhizoctonia root rot of sugarbeet. Crop Protection, 2 (4): $392-408$.

27. Safari, S., Soleimani, M. J., and Zafari, D. 2012. Effects of silicon pretreatment on the activities of defense related enzymes in cucumber inoculated with Fusarium oxysporum. Advances in Environmental Biology, 6 (12): 4001-4007.

28. Uddin, M. M., Akhtar, N., Islam, M. T., and Faruq, A. N. 2011. Effect of Trichoderma harzianum and some selected soil amendment against damping-off disease complex of potato and chilli. The Agriculturists, 9 (182): 106-116.

29. Van Toor, R. F., Jaspers, M. V., and Stewart, A. 2002. Evaluation of Bio-Start TM soil conditioners for control of Sclerotia of Ciborinla camelliae. New Zealand Plant Protection, 55 (1): 146-149.

30. Wang, J. 2012. The effect of combining two biological control microbes on seed and root colonization. Ms.C. Thesis, Submitted to Swedish University of Agricultural Sciences, Uppsala, Sweden. 